ARTICLE

Received 14 Sep 2016 | Accepted 13 Jan 2017 | Published 27 Feb 2017

DOI: $10.1038 /$ ncomms14580

OPEN

\title{
Precise tuning in platinum-nickel/nickel sulfide interface nanowires for synergistic hydrogen evolution catalysis
}

Pengtang Wang ${ }^{1, \star}$, Xu Zhang ${ }^{2, \star}$, Jin Zhang ${ }^{1}$, Sheng Wan ${ }^{3}$, Shaojun Guo ${ }^{3,4,5}$, Gang Lu ${ }^{2}$, Jianlin Yao ${ }^{1}$

$\&$ Xiaoqing Huang ${ }^{1}$

Comprising abundant interfaces, multicomponent heterostructures can integrate distinct building blocks into single entities and yield exceptional functionalities enabled by the synergistic components. Here we report an efficient approach to construct one-dimensional metal/sulfide heterostructures by directly sulfuring highly composition-segregated platinumnickel nanowires. The heterostructures possess a high density of interfaces between platinum-nickel and nickel sulfide components, which cooperate synergistically towards alkaline hydrogen evolution reaction. The platinum-nickel/nickel sulfide heterostructures can deliver a current density of $37.2 \mathrm{~mA} \mathrm{~cm}^{-2}$ at an overpotential of $70 \mathrm{mV}$, which is 9.7 times higher than that of commercial $\mathrm{Pt} / \mathrm{C}$. The heterostructures also offer enhanced stability revealed by longterm chronopotentiometry measurements. The present work highlights a potentially powerful interface-engineering strategy for designing multicomponent heterostructures with advanced performance in hydrogen evolution reaction and beyond.

\footnotetext{
${ }^{1}$ College of Chemistry, Chemical Engineering and Materials Science, Soochow University, Jiangsu 215123, China. ${ }^{2}$ Department of Physics and Astronomy, California State University, Northridge, California 91330, USA. ${ }^{3}$ Department of Materials Science and Engineering, College of Engineering, Peking University, Beijing 100871, China. ${ }^{4}$ BIC-ESAT, College of Engineering, Peking University, Beijing 100871, China. ${ }^{5}$ Department of Energy and Resources Engineering, College of Engineering, Peking University, Beijing 100871, China. * These authors contributed equally to this work. Correspondence and requests for materials should be addressed to S.G. (email: guosj@pku.edu.cn) or to G.L. (email: ganglu@csun.edu) or to X.H. (email: hxq006@suda.edu.cn).
} 
ydrogen $\left(\mathrm{H}_{2}\right)$, as a clean and renewable energy resource, has been considered as a promising alternative to replace the diminishing fossil fuel ${ }^{1-4}$. The grand challenge leading to extensive use of hydrogen energy system is to produce $\mathrm{H}_{2}$ in an efficient and cost-effective manner. Electrochemical water splitting by combining hydrogen evolution reaction (HER) and oxygen evolution reaction is attracting much attention due to its inherent advantages including accessible reactants, stable output, feasibility of largescale production and highly pure product ${ }^{5-10}$. In general, HER is believed to consist of two pathways: Volmer/Tafel pathway or Volmer/Heyrovsky pathway ${ }^{1-13}$. However, the Heyrovsky and the Volmer steps have different expressions in acidic or basic medial ${ }^{11-13}$. The reacting species are $\mathrm{H}_{2} \mathrm{O} / \mathrm{OH}^{-}$in the base solution and $\mathrm{H}^{+}$in the acid solution; thus, the cleavage of $\mathrm{HO}-\mathrm{H}$ bond in $\mathrm{H}_{2} \mathrm{O}$ is crucial for alkaline $\mathrm{HER}^{13,14}$. To date, platinum $(\mathrm{Pt})$ is generally considered as one of the best catalysts towards HER, particularly in acid media ${ }^{15-18}$. However, the HER kinetics of $\mathrm{Pt}$ is much slower in the alkaline condition, resulting in the HER activity that is approximately two to three orders of magnitude lower than in the acidic media ${ }^{19,20}$. This may be attributed to the fact that although $\mathrm{Pt}$ is conducive to the adsorption of reactive hydrogen intermediates $\left(\mathrm{H}_{\mathrm{ads}}\right)$ and their combination into $\mathrm{H}_{2}$ molecules, it is unfortunately not efficient in splitting water into $\mathrm{H}_{\text {ads }}$ in the alkaline solution ${ }^{13,21,22}$. The slow kinetics in the alkaline solution leads to low efficiencies in both water-alkali and chlor-alkali electrolysers. Therefore, introducing 'promoters' with the function to cleave $\mathrm{HO}-\mathrm{H}$ bonds could open new opportunities to further enhance alkaline HER electrocatalysis ${ }^{13,14,23}$. However, which 'promoter' can work well with Pt to yield more efficient and durable HER catalysts remains an open question.

Owing to intrinsic difference in the chemical reactivity of the metallic components, bimetallic nanocrystals with high composition segregation are exploited to develop unusual nanostructures with desirable functionalities ${ }^{24-30}$. They can create interior vacancies or open skeletons such as nanocages and nanoframes by readily sacrificing the relatively active metals ${ }^{27-30}$. Herein, we take the advantage of the highly composition-segregated $\mathrm{Pt}-\mathrm{Ni}$ nanowires (NWs), to create a class of $\mathrm{Pt}_{3} \mathrm{Ni} / \mathrm{NiS}$ heterostructures via a simple yet efficient sulfuration process. The $\mathrm{Pt}_{3} \mathrm{Ni} / \mathrm{NiS}$ heterostructures with a high density of interfaces between $\mathrm{NiS}$ and $\mathrm{Pt}_{3} \mathrm{Ni}$ display excellent HER activity in both acidic and alkaline conditions. Specially, the optimized $\mathrm{Pt}_{3} \mathrm{Ni}_{2} \mathrm{NWs}-\mathrm{S} / \mathrm{C}$ yield the highest activity in the alkaline condition with a current density of $37.2 \mathrm{~mA} \mathrm{~cm}^{-2}$ at an overpotential of $70 \mathrm{mV}$, which is 9.7 times higher than that of the commercial $\mathrm{Pt} / \mathrm{C}$, representing the best electrocatalysts towards alkaline HER, to the best of our knowledge. The density functional theory (DFT) calculations reveal that the synergy between NiS and $\mathrm{Pt}_{3} \mathrm{Ni}$ components can substantially enhance the HER activity in the alkaline solution with $\mathrm{NiS}$ promoting water dissociation, whereas $\mathrm{Pt}_{3} \mathrm{Ni}$ efficiently convert $\mathrm{H}^{+}$to $\mathrm{H}_{2}$. Moreover, these heterostructures also exhibit enhanced HER stability with limited activity decay after a long-term chronopotentiometry run. The unprecedented catalytic performance offered by the novel $\mathrm{Pt}_{3} \mathrm{Ni}$ / NiS heterostructures highlights the importance of interfacial engineering in multicomponent electrocatalysts.

\section{Results}

Synthesis and characterization of PtNi/NiS NWs. A two-step procedure was used to make the unusual $\mathrm{Pt}_{3} \mathrm{Ni} / \mathrm{NiS}$ heterostructures through first making the highly composition-segregated $\mathrm{Pt}-\mathrm{Ni} \mathrm{NWs}^{31}$ and then reacting them with sulfur in oleylamine $(\mathrm{OAm})$ at high temperature. Supplementary Fig. 1 shows the transmission electron microscopy (TEM) images of the pristine Pt-Ni NWs before sulfuration, where abundant of NWs was observed. Through tuning the amounts of $\mathrm{Ni}(\mathrm{acac})_{2}$ and $\mathrm{Pt}(\mathrm{acac})_{2}$ precursors, the molar ratio of $\mathrm{Pt}$ to $\mathrm{Ni}$ in $\mathrm{Pt}-\mathrm{Ni} \mathrm{NWs}$ can be easily tuned from $3: 1$ to $3: 2,3: 3$ and $3: 4$, determined by scanning electron microscopy coupled with energy-dispersive X-ray spectroscopy (SEM-EDS) (Supplementary Fig. 1). The unique part for the composition tuning in Pt-Ni NWs is that with the $\mathrm{Ni}$ increasing, the $\mathrm{Pt}-\mathrm{Ni} \mathrm{NWs}$ become coarser and the composition-segregation features are more obvious, confirmed by both TEM images and powder X-ray diffraction (XRD) patterns (Supplementary Fig. 2).

The highly composition-segregated Pt-Ni NWs were then subjected to sulfuration at high temperature (see details in Methods), as schematically illustrated in Supplementary Fig. 3. Figure 1 and Supplementary Fig. 4 show TEM and high-angle annular dark-field scanning TEM (HAADF-STEM) images of $\mathrm{Pt}_{3} \mathrm{Ni}_{1}$ NWs-S, $\mathrm{Pt}_{3} \mathrm{Ni}_{2}$ NWs-S, $\mathrm{Pt}_{3} \mathrm{Ni}_{3} \mathrm{NWs}-\mathrm{S}$ and $\mathrm{Pt}_{3} \mathrm{Ni}_{4} \mathrm{NWs}-\mathrm{S}$ by the sulfuration of $\mathrm{Pt}_{3} \mathrm{Ni}_{1} \mathrm{NWs}, \mathrm{Pt}_{3} \mathrm{Ni}_{2} \mathrm{NWs}, \mathrm{Pt}_{3} \mathrm{Ni}_{3} \mathrm{NWs}$ and $\mathrm{Pt}_{3} \mathrm{Ni}_{4} \mathrm{NWs}$, respectively. After the sulfuration, all the Pt-Ni NWs-S can nicely maintain their original one-dimensional structure without exception, indicating sulfuration does not destroy the structure of Pt-Ni NWs. Interestingly, new NiS nanoparticles are also observed on the surface of Pt-Ni NWs-S, which leads to the unique interfaces. Moreover, it is clear that the density of the newly produced nanoparticles on the surface increases with increasing the ratio of $\mathrm{Ni}$ to $\mathrm{Pt}$ in the Pt-Ni NWs. The HAADF elemental mappings of Pt-Ni NWs-S shows that, although the distribution of $\mathrm{Pt}$ is mainly located at the interior of NWs, Ni and S evenly distribute throughout the whole NWs (Fig. 1c,f,i,l). This result suggests that the segregated $\mathrm{Ni}$ in $\mathrm{Pt}-\mathrm{Ni}$ NWs could be very reactive and react with the added sulfur powder to in situ produce NiS on the surface. In details, the high reactivity of $\mathrm{Ni}$ with $\mathrm{S}$ would drive the oxidized $\mathrm{Ni}^{2}+$ outward due to highly composition-segregated feature of the pristine $\mathrm{Pt}-\mathrm{Ni}$ NWs. Once the interior Ni species diffuse outward, they would be captured by $\mathrm{S}$ species to form NiS around the NWs immediately. The successful sulfuration of Pt-Ni NWs is also confirmed by the SEM-EDS, where the S signal in Pt-Ni NWs-S is evident and the sulfuration degree increases with the increase of Ni in Pt-Ni NWs (Supplementary Fig. 5). In addition, the inductively coupled plasma-atomic emission spectroscopy (ICP-AES) result (Supplementary Table 1) reveal that the $\mathrm{Pt} / \mathrm{Ni}$ ratios of $\mathrm{Pt}-\mathrm{Ni}$ NWs after the sulfuration are similar to those of the pristine Pt-Ni NWs.

The high-resolution TEM were further carried out to characterize the surface structures and interfaces between Pt-Ni NWs and NiS (Fig. 2a-c). From the Fig. 2a, the NiS nanocrystals grown on the surface of $\mathrm{Pt}_{3} \mathrm{Ni}_{3} \mathrm{NWs}-\mathrm{S}$ exhibit an intimate contact between $\mathrm{Pt}_{3} \mathrm{Ni}$ and $\mathrm{NiS}$, forming a unique $\mathrm{Pt}_{3} \mathrm{Ni} / \mathrm{NiS}$ interface. Figure $2 b, c$ display the magnified image recorded from region $b$ and $c$ marked in Fig. 2a, where the lattice fringes with interplanar spacings are 0.22 and $0.295 \mathrm{~nm}$, corresponding to the (111) plane of $\mathrm{Pt}_{3} \mathrm{Ni}$ and (100) plane of $\mathrm{NiS}$, respectively. XRD analysis of PtNi NWs and Pt-Ni NWs-S was used to further confirm the phase transformation after the sulfuration (Fig. 2d). It is found that the $\mathrm{Pt}_{3} \mathrm{Ni}_{3} \mathrm{NWs}$ have a shoulder peak between $40.5^{\circ}$ and $43.5^{\circ}$ due to the highly composition-segregated feature of $\mathrm{Pt}_{3} \mathrm{Ni}_{3} \mathrm{NWs}$. After the sulfuration, the shoulder peak disappears associated with the formation of a symmetrical peak, which matches well with the $f c c$ $\mathrm{Pt}_{3} \mathrm{Ni}$ phase in previous reports ${ }^{31-33}$ and alloyed $f c c \mathrm{Pt}_{3} \mathrm{Co}$ (Fig. 2d, JCPDS No. 29-0499). Moreover, the weak diffraction peaks of $\mathrm{NiS}$ are also observed in the XRD pattern of $\mathrm{Pt}_{3} \mathrm{Ni}_{3}$ NWs-S, which can be ascribed to the low crystalline feature of the NiS domains (Supplementary Fig. 6). Therefore, all the above results clearly indicate the transformation of the pristine $\mathrm{Pt}-\mathrm{Ni}$ NWs into $\mathrm{Pt}_{3} \mathrm{Ni} / \mathrm{NiS}$ heterostructures by the sulfuration process. 


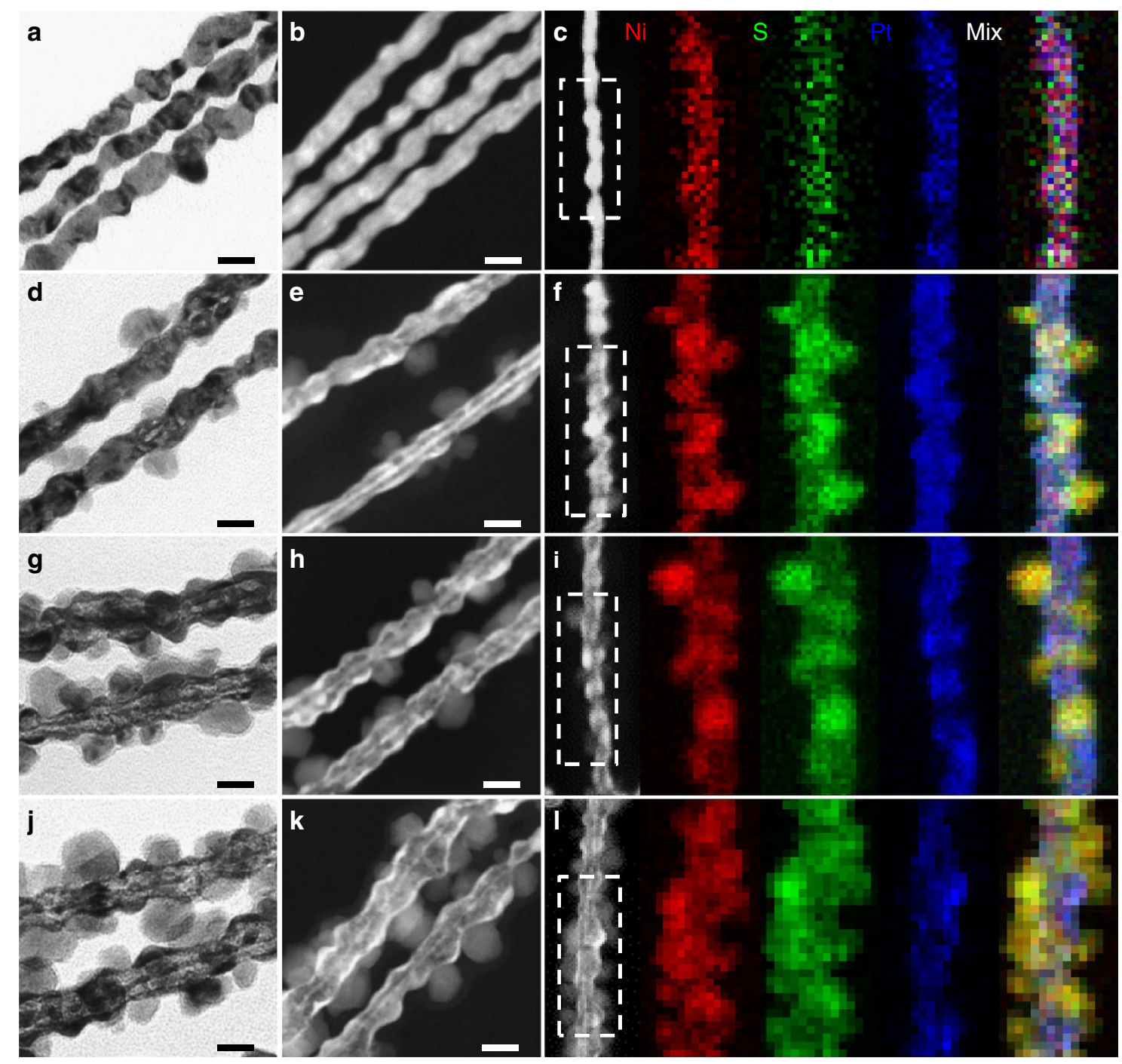

Figure 1 | Morphology characterization and element distribution of Pt-Ni NWs-S. Representative (a,d,g,j) high-magnification TEM images, $(\mathbf{b}, \mathbf{e}, \mathbf{h}, \mathbf{k})$ HAADF-STEM images and (c,f,i,, $\mathbf{l})$ HAADF-STEM images, and corresponding EDS elemental mappings (Ni in red, $\mathrm{S}$ in green and Pt in blue) of (a-c) $\mathrm{Pt}_{3} \mathrm{Ni}_{1} \mathrm{NWs}-\mathrm{S},(\mathbf{d}-\mathbf{f}) \mathrm{Pt}_{3} \mathrm{Ni}_{2} \mathrm{NWs}-\mathrm{S},(\mathbf{g}-\mathbf{i}) \mathrm{Pt}_{3} \mathrm{Ni}_{3} \mathrm{NWs}-\mathrm{S}$ and $(\mathbf{j}-\mathbf{I}) \mathrm{Pt}_{3} \mathrm{Ni}_{4} \mathrm{NWs}-\mathrm{S}$. Scale bars, $20 \mathrm{~nm}(\mathbf{a}, \mathbf{b}, \mathbf{d}, \mathbf{e}, \mathbf{g}, \mathbf{h}, \mathbf{j}, \mathbf{k})$.

X-ray photoelectron spectroscopy (XPS) was also used to trace the chemical states of different elements after the sulfuration (Fig. 2e-g). To be specific, the broad S $2 p$ XPS peak is fitted into four peaks (Fig. 2e). The peaks located at 161.5 and $162.4 \mathrm{eV}$ are attributed to the $2 p 3 / 2$ and $2 p 1 / 2$ orbitals of divalent sulfide $\left(\mathrm{S}^{2-}\right)$, respectively. The peak centred at 162.7 and $163.8 \mathrm{eV}$ suggests the existence of bridging $\mathrm{S}_{2}^{2-}$ (ref. 34). The ratio of $\mathrm{S}^{2-} / \mathrm{S}_{2}^{2-}$, calculated into $0.73 / 1$, means that the $\mathrm{S}^{2-}$ and $\mathrm{S}_{2}^{2-}$ are co-existed in nickel sulfide. For the simplification, we use NiS to denote the nickel sulfide herein. Figure $2 \mathrm{f}$ shows $\mathrm{Ni}$ has both metallic and oxidized state, attributed to the $\mathrm{NiS}$ and $\mathrm{Pt}_{3} \mathrm{Ni}$ phases, respectively. XPS result reveals the $\mathrm{Pt}^{0}$ and $\mathrm{Pt}^{2+}$ are also coexisted in the $\mathrm{Pt}_{3} \mathrm{Ni}_{3}$ NWs-S (Fig. 2g). All the above results support that $\mathrm{Pt}_{3} \mathrm{Ni}_{3} \mathrm{NWs}-\mathrm{S}$ has been well evolved into $\mathrm{Pt}_{3} \mathrm{Ni} / \mathrm{NiS}$ heterostructure after the sulfuration.

Pt-Ni NWs-S with tunable interface contact can be made by using Pt-Ni NWs with different compositions as the templates (Supplementary Figs 7-9). Except for $\mathrm{Pt}_{3} \mathrm{Ni}_{1} \mathrm{NWs}-\mathrm{S}$, the obvious interface between NiS and $\mathrm{Pt}_{3} \mathrm{Ni}$ is observed in the $\mathrm{Pt}_{3} \mathrm{Ni}_{2}$ NWs-S and $\mathrm{Pt}_{3} \mathrm{Ni}_{4} \mathrm{NWs-S}$ (Supplementary Figs $8 \mathrm{a}$ and $9 \mathrm{a}$ ). Furthermore, the XRD patterns of various Pt-Ni NWs-S display similar changes to that of the $\mathrm{Pt}_{3} \mathrm{Ni}_{3} \mathrm{NWs}$-S, where the shoulder peak disappears associated with the presence of $\mathrm{Pt}_{3} \mathrm{Ni}$ and $\mathrm{NiS}$ peaks. It is worth mentioning that there are no obvious interfacial changes for $\mathrm{Pt}_{3} \mathrm{Ni}_{1}$ NWs after sulfuration due to the high stability of $\mathrm{Pt}_{3} \mathrm{Ni}_{1}$ alloy phase, as revealed by the TEM, STEM and high-resolution TEM (Supplementary Fig. 7). The presence of sulfur signals of $\mathrm{Pt}_{3} \mathrm{Ni}_{1} \mathrm{NWs}-\mathrm{S}$ in the SEM-EDS and XPS pattern are likely to be caused by the contamination of sulfur species during the sulfuration (Supplementary Fig. 7), as the sulfur signals can be largely reduced after the wash treatment of the $\mathrm{Pt}_{3} \mathrm{Ni}_{1} \mathrm{NWs}-\mathrm{S}$ (Supplementary Fig. 10). Moreover, the intensities of $\mathrm{S}^{2-} 2 p 3 / 2$ and $2 p 1 / 2$ in XPS patterns of Pt-Ni NWs-S with different compositions are gradually increased with increasing the amount of $\mathrm{Ni}$, showing that high amount of $\mathrm{Ni}$ in Pt-Ni NWs can facilitate the formation of NiS after the sulfuration.

HER performance of PtNi/NiS NWs. The HER activities of pristine Pt-Ni NWs and Pt-Ni NWs-S were investigated using the linear sweep voltametry at a scan rate of $10 \mathrm{mV} \mathrm{s}^{-1}$ and room temperature without insulation resistance compensation in $1 \mathrm{M}$ $\mathrm{KOH}$ solution. Before the HER measurements, the Pt-Ni NWs and Pt-Ni NWs-S with different compositions were uniformly loaded onto a commercial carbon black with the aid of sonication (Supplementary Figs 11 and 12). The carbon supported Pt-Ni 


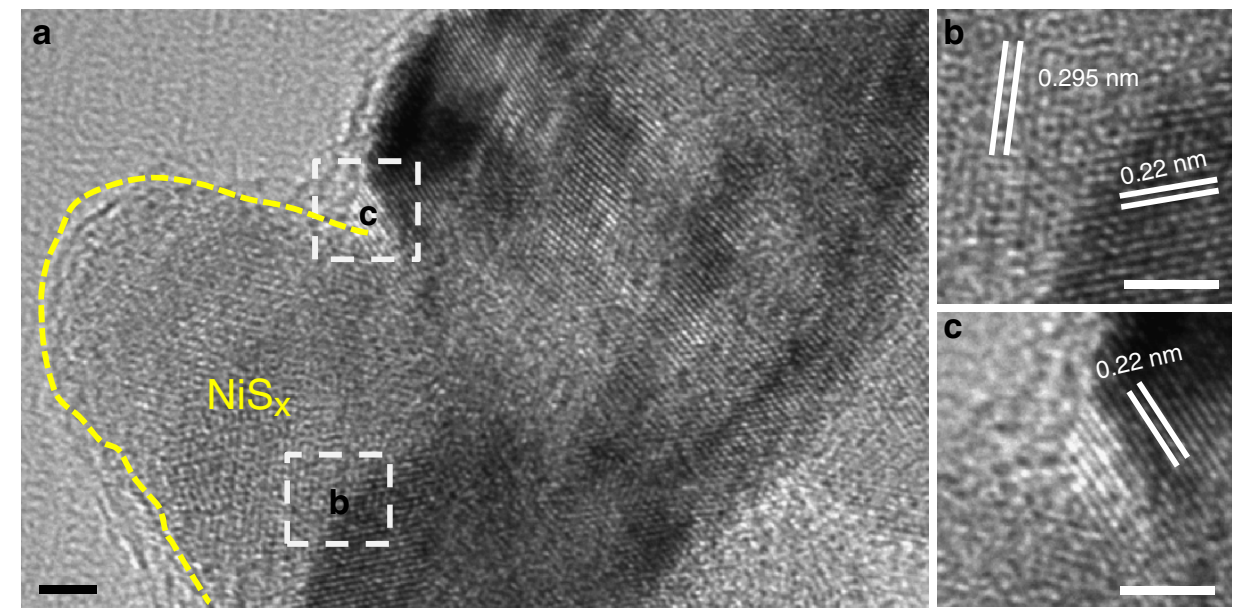

d

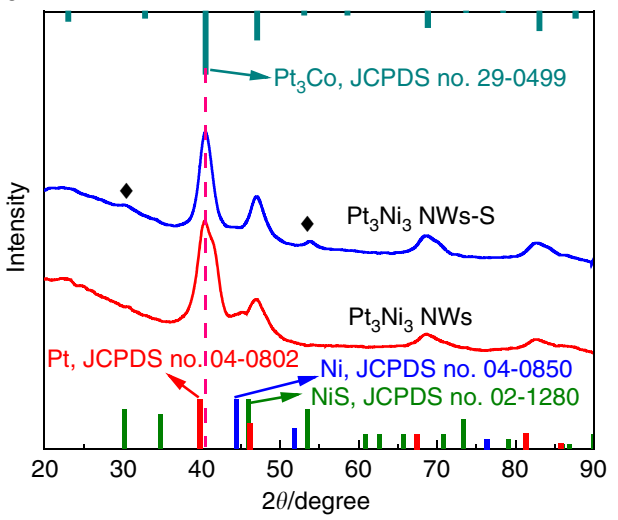

f

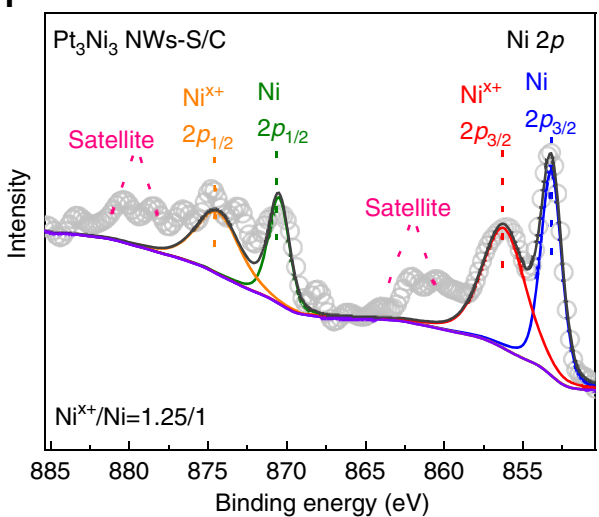

e

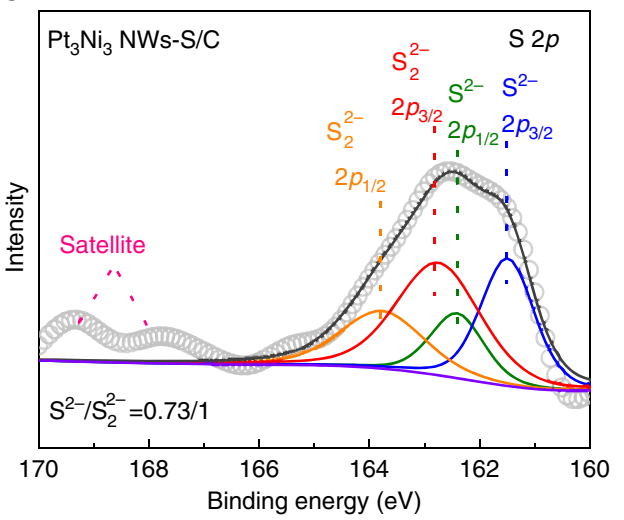

g

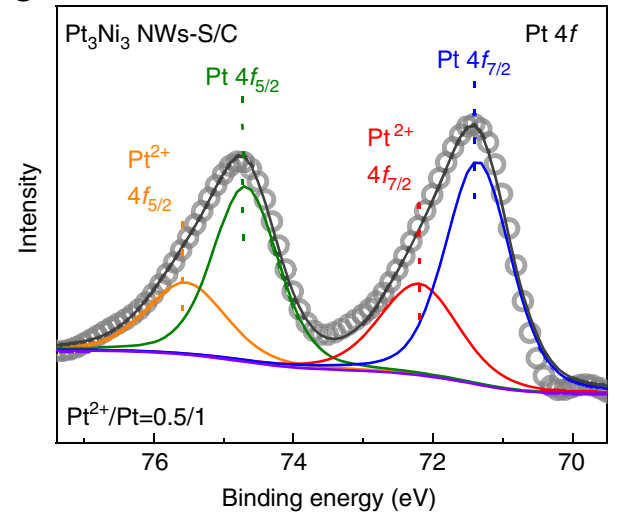

Figure 2 | Interface and phase characterizations of $\mathbf{P t}_{\mathbf{3}} \mathbf{N i}_{\mathbf{3}} \mathbf{N W s}$-S. Representative (a) high-resolution TEM (HRTEM) image of Pt $\mathrm{Ni}_{3} \mathrm{NWs}-\mathrm{S}$ and $(\mathbf{b}, \mathbf{c})$ the magnified HRTEM images recorded from regions $b$ and $c$ marked in $\mathbf{a}$. The yellow dashed curve highlights the $\mathrm{NiS}_{x}$ particle on the surface of the $\mathrm{Pt}_{3} \mathrm{Ni} \mathrm{NWs}$. (d) XRD patterns of $\mathrm{Pt}_{3} \mathrm{Ni}_{3} \mathrm{NWs}-\mathrm{S}$ and $\mathrm{Pt}_{3} \mathrm{Ni}_{3} \mathrm{NWs}$. The diamond symbols denote the emerging $\mathrm{NiS}_{3}$ in $\mathrm{Pt}_{3} \mathrm{Ni}_{3} \mathrm{NWs}-\mathrm{S}$. XPS patterns of (e) $\mathrm{S} 2 p$, (f) $\mathrm{Ni} 2 p$ and (g) Pt $4 f$ of $\mathrm{Pt}_{3} \mathrm{Ni}_{3} \mathrm{NWs}-\mathrm{S}$. Scale bars, $2 \mathrm{~nm}$ in $\mathbf{a}-\mathbf{c}$.

NWs or Pt-Ni NWs-S (denoted as Pt-Ni NWs-S/C and Pt-Ni $\mathrm{NWs} / \mathrm{C}$ ), dispersed in a mixture of ethanol/water/Nafion solution, were dropped onto a rotating disk electrode for HER test. The loading amounts of Pt for all the catalysts were fixed at $3 \mu \mathrm{g}$ based on the ICP-AES. Figure $3 \mathrm{a}-\mathrm{d}$ shows the HER activities of Pt-Ni $\mathrm{NWs-S/C}$ are highly dependent on their compositions, where the sulfuration in $\mathrm{Pt}_{3} \mathrm{Ni}_{1}$ and $\mathrm{Pt}_{3} \mathrm{Ni}_{4} \mathrm{NWs}$ does not enhance its catalytic performance for HER (Fig. 3a,d). However, the overpotentials of $\mathrm{Pt}_{3} \mathrm{Ni}_{2}$ NWs-S/C and $\mathrm{Pt}_{3} \mathrm{Ni}_{3}$ NWs-S/C for HER decrease from 60 to $51 \mathrm{mV}$ and 65 to $59 \mathrm{mV}$, respectively (Fig. 3b,c). Among Pt-Ni NWs with various compositions, the
$\mathrm{Pt}_{3} \mathrm{Ni}_{2} \mathrm{NWs}-\mathrm{S} / \mathrm{C}$ shows the maximum HER activity enhancement (Supplementary Fig. 13). Furthermore, the HER activities of different Pt-Ni NWs-S/C were compared with commercial Pt/C, revealing the HER activities follow the sequence $\mathrm{Pt}_{3} \mathrm{Ni}_{2} \mathrm{NWs}-\mathrm{S} /$ $\mathrm{C}>\mathrm{Pt}_{3} \mathrm{Ni}_{3} \mathrm{NWs}-\mathrm{S} / \mathrm{C}>\mathrm{Pt}_{3} \mathrm{Ni}_{1} \mathrm{NWs}-\mathrm{S} / \mathrm{C}>\mathrm{Pt}_{3} \mathrm{Ni}_{4} \mathrm{NWs}-\mathrm{S} / \mathrm{C}>\mathrm{Pt} /$ $\mathrm{C}$ (Fig. 3e). The current densities of these five catalysts at $-0.07 \mathrm{~V}$ versus RHE are summarized in Fig. 3f. The current density of $\mathrm{Pt}_{3} \mathrm{Ni}_{2} \mathrm{NWs}-\mathrm{S} / \mathrm{C}$ at $-0.07 \mathrm{~V}$ is $19.1 \mathrm{~mA} \mathrm{~cm}{ }^{-2}, 5.6$ times higher than that of the $\mathrm{Pt} / \mathrm{C}\left(3.42 \mathrm{~mA} \mathrm{~cm}^{-2}\right)$, demonstrating that the $\mathrm{Pt}_{3} \mathrm{Ni}_{2} \mathrm{NWs}-\mathrm{S} / \mathrm{C}$ with unique $\mathrm{Pt}_{3} \mathrm{Ni} / \mathrm{NiS}$ interface can largely promote the HER activity in alkaline medium. 
a

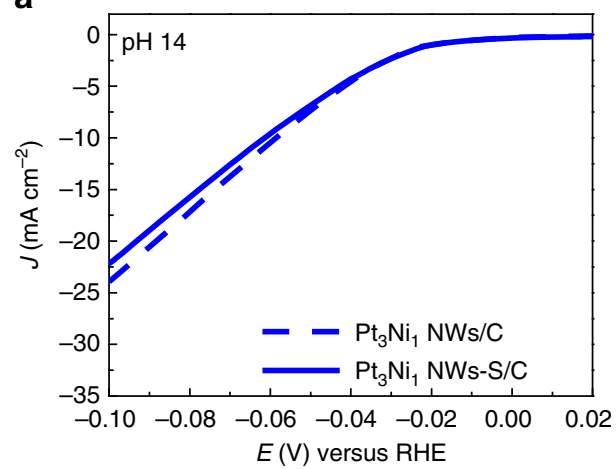

C

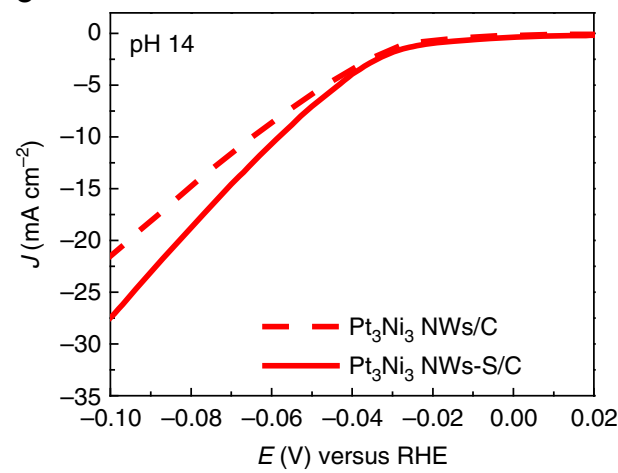

e

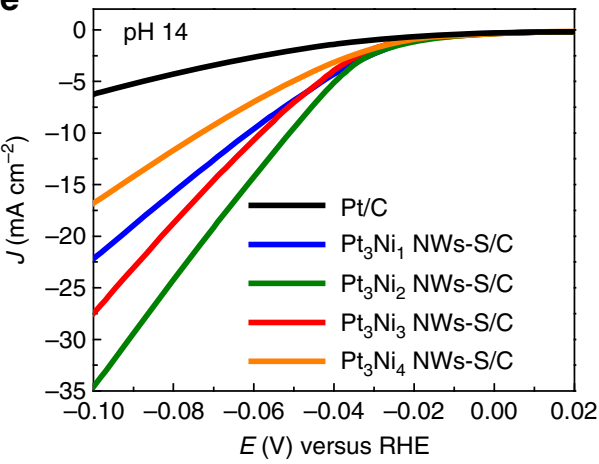

b

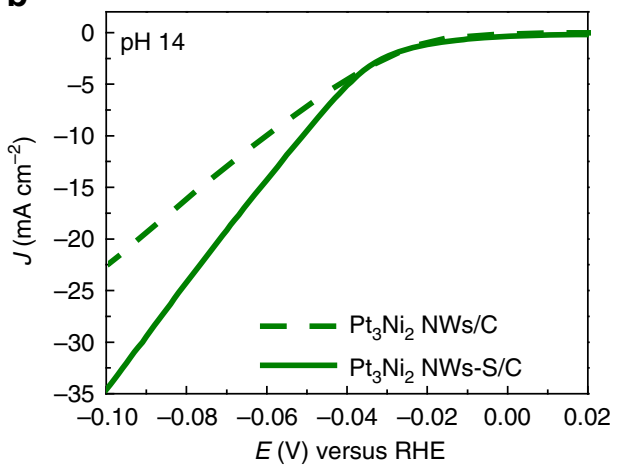

d

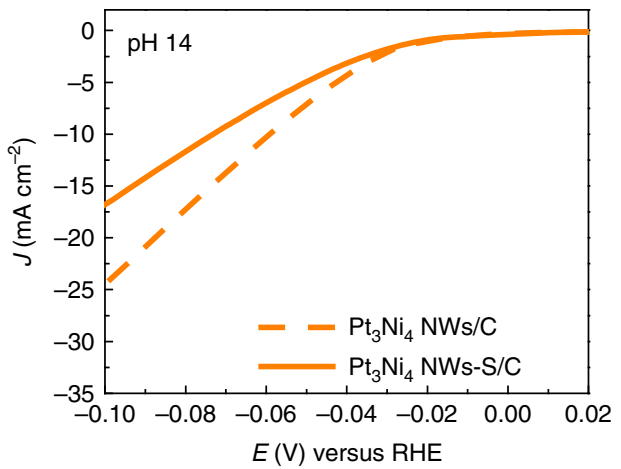

f

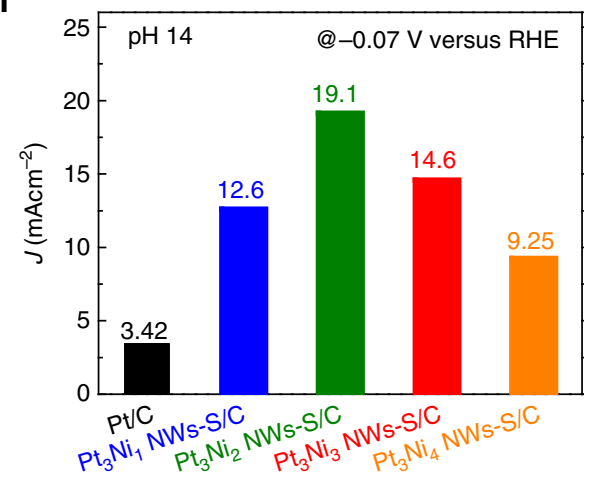

Figure 3 | Electrocatalytic activities of different $\mathbf{P t - N i} \mathbf{N W s}-\mathbf{S} / \mathbf{C}$ in the $\mathbf{p H}$ of 14. HER polarization curves of (a) $\mathrm{Pt}_{3} \mathrm{Ni}_{1} \mathrm{NWs} \mathrm{S} / \mathrm{C}$ and $\mathrm{Pt} \mathrm{Ni}_{3} \mathrm{Ni}_{1} \mathrm{NWs} / \mathrm{C}$, (b) $\mathrm{Pt}_{3} \mathrm{Ni}_{2} \mathrm{NWs}-\mathrm{S} / \mathrm{C}$ and $\mathrm{Pt}_{3} \mathrm{Ni}_{2} \mathrm{NWs} / \mathrm{C}$, (c) $\mathrm{Pt}_{3} \mathrm{Ni}_{3} \mathrm{NWs}-\mathrm{S} / \mathrm{C}$ and $\mathrm{Pt}_{3} \mathrm{Ni}_{3} \mathrm{NWs} / \mathrm{C}$, and (d) $\mathrm{Pt}_{3} \mathrm{Ni}_{4} \mathrm{NWs}-\mathrm{S} / \mathrm{C}$ and $\mathrm{Pt}_{3} \mathrm{Ni}_{4} \mathrm{NWs} / \mathrm{C}$ at pH 14 , at room temperature. (e) HER polarization curves of different Pt-Ni NWs-S/C and Pt/C at pH of 14 at room temperature. (f) Histograms of current densities at $-0.07 \mathrm{~V}$ versus RHE from e. All the polarization curves were recorded at a scan rate of $10 \mathrm{mVs}^{-1}$ and a rotation rate of 1,600 r.p.m. with no insulation resistance compensation and all the current densities were normalized to the geometric area of working electrode.

Owing to the unexpected activity enhancement of $\mathrm{Pt}_{3} \mathrm{Ni}_{2}$ NWs-S/C for HER at $\mathrm{pH} 14$, it stimulated us to explore whether it is also effective in other $\mathrm{pH}$ conditions. To this end, we carried out the detailed HER measurements in $\mathrm{pH}$ of $13(0.1 \mathrm{M} \mathrm{KOH})$, $\mathrm{pH}$ of $1\left(0.05 \mathrm{M} \mathrm{H}_{2} \mathrm{SO}_{4}\right)$ and $\mathrm{pH}$ of $0\left(0.5 \mathrm{M} \mathrm{H}_{2} \mathrm{SO}_{4}\right)$, respectively. The results show that the $\mathrm{Pt}_{3} \mathrm{Ni}_{2} \mathrm{NWs-S/C}$ still exhibits the best HER activity among three catalysts. However, the overall activity enhancement at $\mathrm{pH} 13$ is much lower than that at $\mathrm{pH} 14$, suggesting that the $\mathrm{Pt}_{3} \mathrm{Ni}_{2} \mathrm{NWs}-\mathrm{S} / \mathrm{C}$ is more susceptible at higher alkaline condition. The HER activities of $\mathrm{Pt}-\mathrm{Ni} \mathrm{NWs}-\mathrm{S} / \mathrm{C}$ in acidic media are also displayed in Fig. 4b,c, respectively. Similarly, the $\mathrm{Pt}_{3} \mathrm{Ni}_{2} \mathrm{NWs}-\mathrm{S} / \mathrm{C}$ also display the best activity, but it is only slightly better than commercial Pt/C. To make a quantitative activity comparison, the current densities of $\mathrm{Pt}_{3} \mathrm{Ni}_{2} \mathrm{NWs}-\mathrm{S} / \mathrm{C}$, $\mathrm{Pt}_{3} \mathrm{Ni}_{2} \mathrm{NWs} / \mathrm{C}$ and $\mathrm{Pt} / \mathrm{C}$ at $-0.07 \mathrm{~V}$ at different $\mathrm{pH}$ are shown in Fig. 4d. It shows that the $\mathrm{Pt}_{3} \mathrm{Ni}_{2} \mathrm{NWs-S/C}$ reaches the current density of $49.7,5.50$ and $4.90 \mathrm{~mA} \mathrm{~cm}^{-2}$ at $-0.07 \mathrm{~V}$ at the $\mathrm{pH} 0$, 1 and 13, respectively. Such activity variations of Pt-Ni NWs-S/C at different $\mathrm{pH}$ values demonstrate that the HER kinetics on $\mathrm{Pt}-\mathrm{Ni} \mathrm{NWs}-\mathrm{S} / \mathrm{C}$ is highly sensitive to the $\mathrm{pH}$ condition.

Other Pt-Ni NWs-S/C and Pt-Ni NWs/C with different compositions were also investigated, as shown in Supplementary Figs 14-16. The activities of both $\mathrm{Pt}_{3} \mathrm{Ni}_{1} \mathrm{NWs}$ $\mathrm{S} / \mathrm{C}$ and $\mathrm{Pt}_{3} \mathrm{Ni}_{4} \mathrm{NWs}-\mathrm{S} / \mathrm{C}$ at $\mathrm{pH}$ of 13 are inferior to their corresponding Pt-Ni NWs/C, similar to the trend at $\mathrm{pH} 14$. In acidic condition, all the Pt-Ni NWs-S/C exhibit better activities than the Pt-Ni NWs/C and Pt/C. Comparing with the activities of Pt-Ni NWs-S/C with different compositions in different $\mathrm{pH}$ values (Fig. 3e and Supplementary Fig. 17), we can find that the HER activity difference of Pt-Ni NWs-S/C is more significant in alkaline condition and the activity of Pt-Ni NWs-S is more susceptible at higher alkaline condition. For this point, we 
a

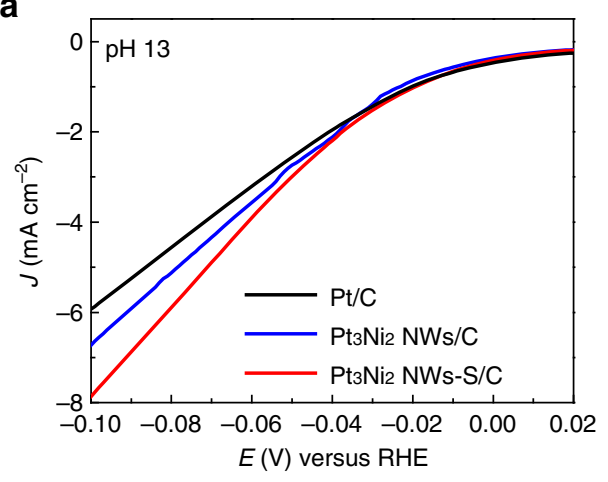

C

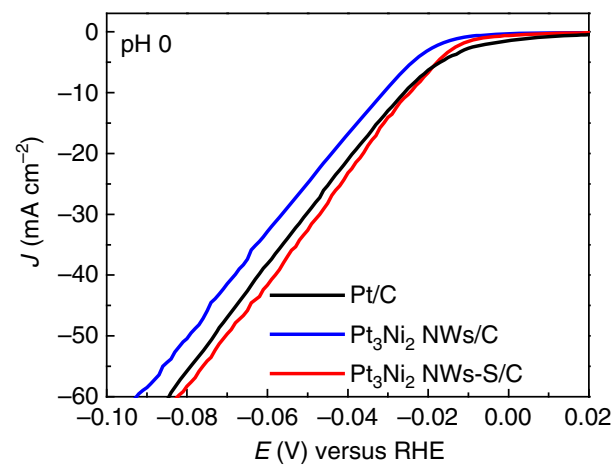

e

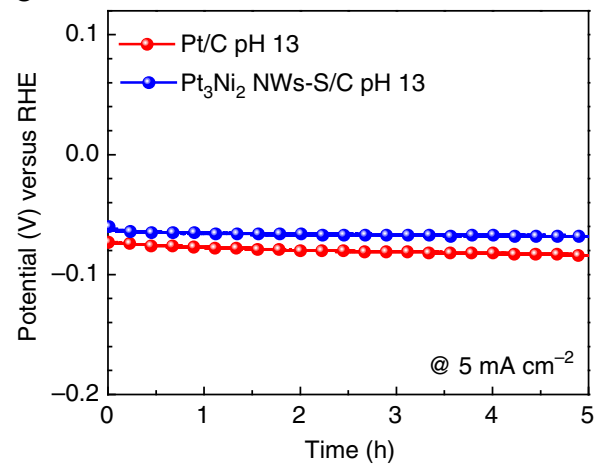

b

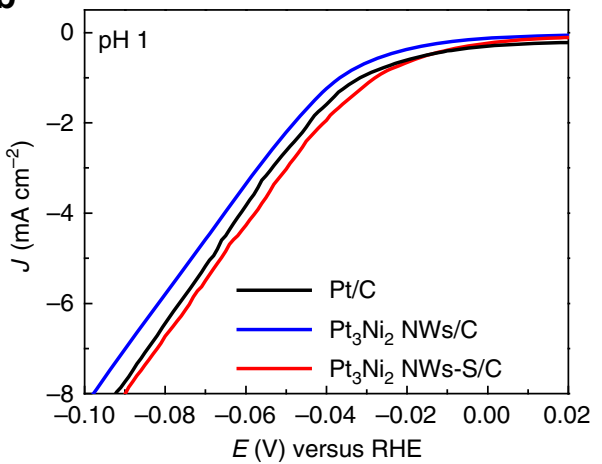

d

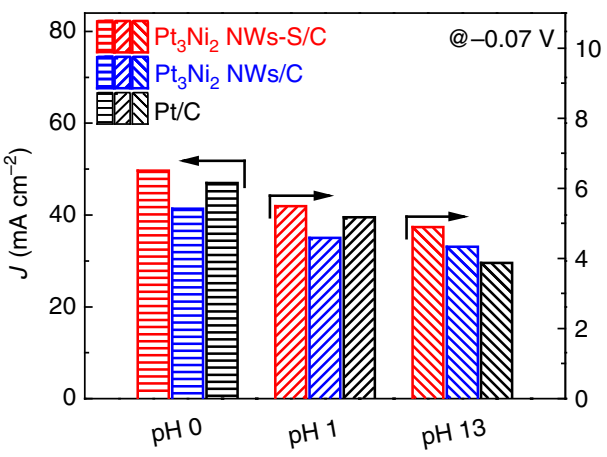

f

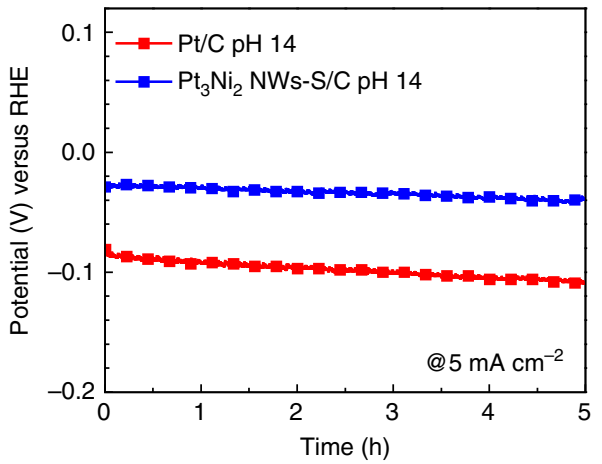

Figure 4 | Electrocatalytic activities and stabilities of $\mathbf{P t}_{\mathbf{3}} \mathbf{N i}_{\mathbf{2}} \mathbf{N W s}-\mathbf{S} / \mathbf{C}$ in different $\mathbf{p H}$ conditions. $\mathrm{HER}$ polarization curves of $\mathrm{Pt}_{3} \mathrm{Ni}_{2} \mathrm{NWs}_{\mathrm{C}} \mathrm{C}, \mathrm{Pt}_{3} \mathrm{Ni}_{2}$ NWs-S/C and Pt/C at pH (a) 13, (b) 1 and (c) 0 , at room temperature. (d) Histograms of comparative current densities at $-0.07 \mathrm{~V}$ versus RHE from a-c. The polarization curves in a-c were recorded at a scan rate of $10 \mathrm{mV} \mathrm{s}^{-1}$ and a rotation rate of 1,600 r.p.m. with no insulation resistance compensation and the current densities were normalized to the geometric area of working electrode. Chronopotentiometry of $\mathrm{Pt}_{3} \mathrm{Ni}_{2} \mathrm{NWs}-\mathrm{S} / \mathrm{C}$ and $\mathrm{Pt} / \mathrm{C}$ under the current density of $5 \mathrm{~mA} \mathrm{~cm}-{ }^{2}$ at pH (e) 13 and (f) 14 at room temperature.

suppose that it might relate to the concentration of $\mathrm{K}^{+}$and the unique heterostructure between $\mathrm{Pt}_{3} \mathrm{Ni} \mathrm{NWs}$ and $\mathrm{NiS}$. As demonstrated by Subbaraman et al. ${ }^{13}$, the presence of hydrated cations in the vicinity of the $\mathrm{Pt}-\mathrm{Ni}(\mathrm{OH})_{2}$ interfaces can interact with water molecules and alter the orientation of water through non-covalent interaction of $\mathrm{Ni}(\mathrm{OH})_{2}-\mathrm{Li}^{+}{ }_{-} \mathrm{OH}-\mathrm{H}$, which enhance the generation of hydrogen intermediates and thus result in the improvement of HER activity. As similar interaction of NiS- $\mathrm{K}^{+}-\mathrm{OH}-\mathrm{H}$ could happen in the vicinity of Pt-Ni NWs-S, the higher HER activity of Pt-Ni NWs-S in pH of 14 than in $\mathrm{pH}$ of 13 can be partially ascribed to the increased concentration of $\mathrm{K}^{+}$. Such hypothesis has been confirmed experimentally, where in the $\mathrm{pH}$ of 13 , the HER activity of $\mathrm{Pt}_{3} \mathrm{Ni}_{3} \mathrm{NWs}-\mathrm{S}$ increases with the addition of $\mathrm{K}^{+}$(Supplementary Fig. 18). The HER activities with insulation resistance compensation at $\mathrm{pH} 13$ and $\mathrm{pH} 14$ were further obtained and compared with various reported results (Supplementary Fig. 19 and Supplementary Table 2). It is found that $\mathrm{Pt}_{3} \mathrm{Ni}_{2} \mathrm{NWs}-\mathrm{S} / \mathrm{C}$ exhibits the highest activity of 37.2 and $20.2 \mathrm{~mA} \mathrm{~cm}^{-2}$ at $\mathrm{pH} 14$ and 13 at $-0.07 \mathrm{~V}$ among all different catalysts, respectively, 9.7 times and 2.4 times higher than those of the commercial $\mathrm{Pt} / \mathrm{C}\left(3.82 \mathrm{~mA} \mathrm{~cm}^{-2}\right.$ at $\mathrm{pH} 14$ and $8.41 \mathrm{~mA} \mathrm{~cm}^{-2}$ at $\mathrm{pH} \mathrm{13),} \mathrm{also} \mathrm{representing} \mathrm{the} \mathrm{highest} \mathrm{alkaline}$ HER activity among all the previously reported catalysts.

The HER stability of $\mathrm{Pt}_{3} \mathrm{Ni}_{2}$ NWs-S/C was tested using chronopotentiometry technique and further compared with the commercial $\mathrm{Pt} / \mathrm{C}$. Figure $4 \mathrm{e}$ shows the chronopotentiometric curves of $\mathrm{Pt}_{3} \mathrm{Ni}_{2} \mathrm{NWs}-\mathrm{S} / \mathrm{C}$ and $\mathrm{Pt} / \mathrm{C}$ at a current density of $5 \mathrm{~mA} \mathrm{~cm}^{-2}$ at $\mathrm{pH}$ 13. It shows that $\mathrm{Pt}_{3} \mathrm{Ni}_{2} \mathrm{NWs}-\mathrm{S} / \mathrm{C}$ display the long-term stability without obvious potential shift. The stability of $\mathrm{Pt}_{3} \mathrm{Ni}_{2} \mathrm{NWs}-\mathrm{S} / \mathrm{C}$ at $\mathrm{pH}$ of 14 were also tested (Fig. $4 \mathrm{f}$ ). We can see that the HER activity loss of $\mathrm{Pt}_{3} \mathrm{Ni}_{2} \mathrm{NWs}-\mathrm{S} / \mathrm{C}$ is less than that of $\mathrm{Pt} / \mathrm{C}$. The TEM images of $\mathrm{Pt}_{3} \mathrm{Ni}_{2} \mathrm{NWs}-\mathrm{S} / \mathrm{C}$ after $5 \mathrm{~h}$ chronopotentiometry test shows that the interfaces of $\mathrm{Pt}_{3} \mathrm{Ni}_{2} \mathrm{NWs}-\mathrm{S} / \mathrm{C}$ can be largely maintained (Supplementary Fig. 20), whereas the Pt/C 
has obvious agglomeration (Supplementary Fig. 21). Moreover, the SEM-EDS and XPS (Supplementary Fig. 20c,d) results reveal that the atomic ratio of $\mathrm{Ni}$ to $\mathrm{S}$ in $\mathrm{Pt}_{3} \mathrm{Ni}_{2} \mathrm{NWs}$-S/C shows almost no change after stability test. Even after the chronopotentiometry tests at very high current density and longer time, the content of $S$ and $\mathrm{Ni}$ could be largely maintained (Supplementary Fig. 22), further confirming the good stability of the $\mathrm{Pt}_{3} \mathrm{Ni}_{2} \mathrm{NWs}$-S likely to be due to its larger nanostructure than that of Pt nanoparticles.

\section{Discussion}

Here we propose that the synergy between the $\mathrm{Pt}_{3} \mathrm{Ni}$ and $\mathrm{NiS}$ components is the main factor in enhancing the alkaline HER activity. To be specific, the $\mathrm{H}_{2} \mathrm{O}$ in basic media would adsorb electron to be dissociated into intermediate $\mathrm{H}_{\mathrm{ads}}$ and $\mathrm{OH}^{-}$by NiS through the Volmer step. Owing to the unfilled $d$ orbitals of $\mathrm{Ni}^{2+}$, the NiS can also immobilize the $\mathrm{OH}^{-}$by the stronger electrostatic affinity to avoid the $\mathrm{OH}^{-}$block the active site of Pt. The generated $\mathrm{H}_{\text {ads }}$ would be adsorbed on a nearby empty Pt site and further be converted into $\mathrm{H}_{2}$ readily through the Tafel step or Heyrovsky step. To examine how the individual components of $\mathrm{NiS} / \mathrm{Pt}_{3} \mathrm{Ni}$ cooperate synergistically to enhance alkaline HER activity, we performed DFT calculations for the key reaction steps in alkaline HER, including the water dissociation reaction and the adsorption/combination of reactive hydrogen intermediates $\left(\mathrm{H}_{\mathrm{ads}}\right)$. For HER in alkaline solution, water supplies hydrogen and the dissociation of water is considered as a key ratedetermining step ${ }^{12,13}$. As shown in Fig. 5a, the energy barrier for breaking the $\mathrm{OH}-\mathrm{H}$ bond in water is $0.89 \mathrm{eV}$ on $\mathrm{Pt}$ (111) surface and such a high energy barrier clearly hinders the dissociation of water to $\mathrm{H}_{\text {ads. }}$. Strikingly, the dissociation barrier is reduced to $0.32 \mathrm{eV}$ on NiS (100) surface. Thus, the NiS surface can promote water dissociation substantially and increase the rate of $\mathrm{H}_{\mathrm{ads}}$ formation by orders of magnitude. Subsequently, the produced $\mathrm{H}_{\mathrm{ads}}$ would combine to form $\mathrm{H}_{2}$ and the key quantity of interest is the free energy of hydrogen adsorption $G_{\mathrm{H}^{*}}$ on the surface, which is often used as a descriptor for $\mathrm{HER}^{35}$. We calculated $G_{\mathrm{H}^{*}}$ on Pt (111), $\mathrm{Pt}_{3} \mathrm{Ni}$ (111) and NiS (100) surfaces (Fig. 5b). As the hydrogen binding energy $G_{\mathrm{H}^{*}}$ on the NiS surface is much stronger than the optimal value $\left(G_{\mathrm{H}^{*}}=0\right)$, the desorption of $\mathrm{H}_{\mathrm{ads}}$ is suppressed significantly and $\mathrm{H}_{2}$ production is thus hindered. Consequently, the HER kinetic is sluggish on the NiS surface. In contrast, we find that the hydrogen-binding energies $G_{\mathrm{H}^{*}}$ on $\mathrm{Pt}_{3} \mathrm{Ni}$ (111) surface are much smaller and closer to the optimal value; two inequivalent adsorption sites on $\mathrm{Pt}_{3} \mathrm{Ni}$ (111) surface (blue and red) were considered. In fact, one of the two sites (red) has almost identical $G_{\mathrm{H}^{*}}$ as that on $\mathrm{Pt}$ (111), suggesting that $\mathrm{Pt}_{3} \mathrm{Ni}$ can be almost as efficient as $\mathrm{Pt}$ for the production of $\mathrm{H}_{2}$. It should be noted that hollowness is probably not the main reason for the HER activity enhancement, as the HER activity of the solid $\mathrm{Pt}_{3} \mathrm{Ni}_{3}$ NWs-S is similar to that of the $\mathrm{Pt}_{3} \mathrm{Ni}_{3} \mathrm{NWs}$-S with hollow feature (Supplementary Fig. 23). Therefore, the synergy between NiS for promoting water dissociation and $\mathrm{Pt}_{3} \mathrm{Ni}$ for enhancing $\mathrm{H}_{\mathrm{ads}}$ adsorption and combination renders the $\mathrm{NiS} / \mathrm{Pt}_{3} \mathrm{Ni}$ heterostructure as an exceptional catalyst for alkaline HER.

The synergistic effect of the $\mathrm{Pt}_{3} \mathrm{Ni} / \mathrm{NiS}$ heterostructure is also responsible for the activity variations among Pt-Ni NW-S/C. For the $\mathrm{Pt}_{3} \mathrm{Ni}_{1} \mathrm{NWs}-\mathrm{S} / \mathrm{C}$, the synergistic effect is too weak due to the limited intimate interface between $\mathrm{Pt}_{3} \mathrm{Ni}$ and $\mathrm{NiS}$, resulting in the stagnant dissociation of the HO-H by NiS, thus reducing the HER activity. With the proper intimate interface, $\mathrm{Pt}_{3} \mathrm{Ni}_{2} \mathrm{NWs}-\mathrm{S}$ can maximize the synergistic effect and achieve the best HER activity. However, the $\mathrm{Pt}_{3} \mathrm{Ni}_{3}$ NWs-S and $\mathrm{Pt}_{3} \mathrm{Ni}_{4}$ NWs-S with higher density of interface will make the $\mathrm{Pt}_{3} \mathrm{Ni}$ core be wrapped too compact to have enough active sites for Pt to absorb and recombine the $\mathrm{H}_{\mathrm{ads}}$ into $\mathrm{H}_{2}$, leading to the gradually decreased
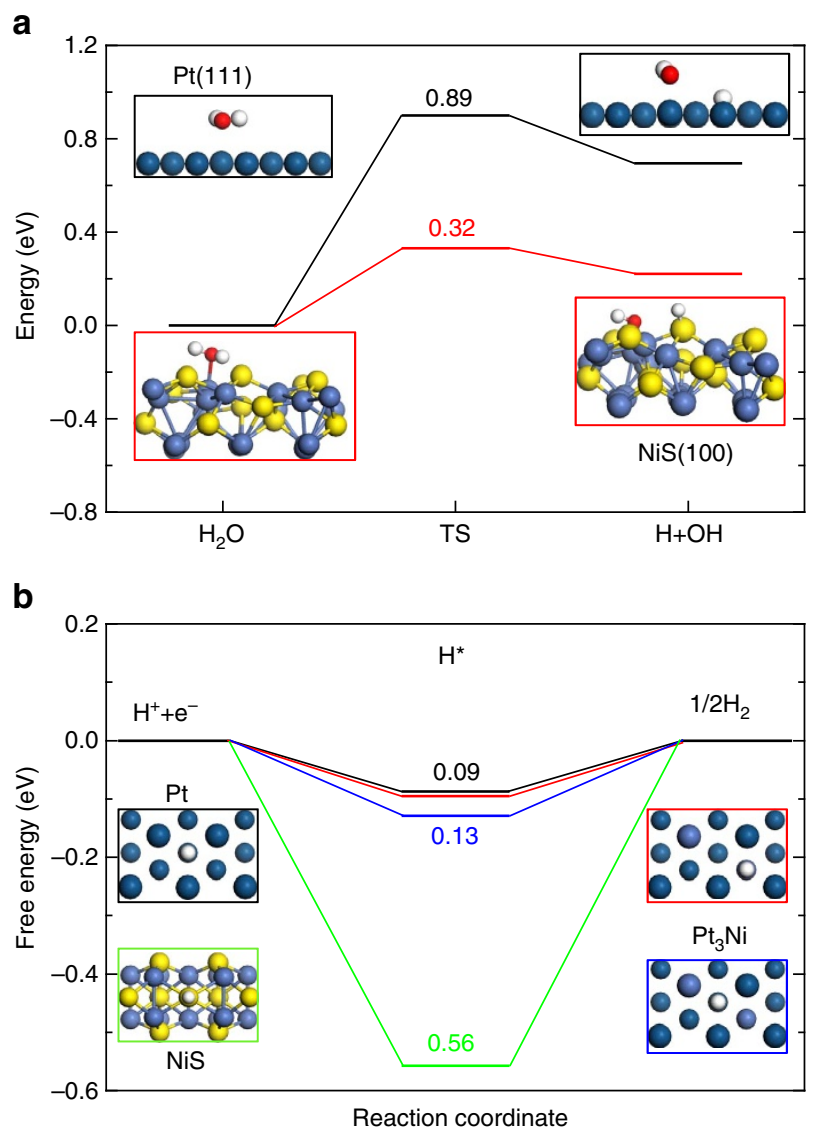

Figure 5 | DFT simulations of HER. (a) Reaction energy diagram of water dissociation on the Pt (111) surface (black) and NiS (100) surface (red). The initial state $\left(\mathrm{H}_{2} \mathrm{O}\right)$, the transition state $(\mathrm{TS})$ and the final state $(\mathrm{H}+\mathrm{OH})$ are indicated in the diagram with the corresponding energy barrier on the two surfaces. (b) Free-energy barriers for HER on the Pt (111) surface (black), $\mathrm{Pt}_{3} \mathrm{Ni}(111)$ surface (red and blue) and $\mathrm{NiS}(100)$ surface (green) at $U=0 \mathrm{~V}$. The red, white, yellow, dark blue and light blue spheres represent $\mathrm{O}, \mathrm{H}, \mathrm{S}, \mathrm{Pt}$ and $\mathrm{Ni}$ atoms, respectively.

activities. Hence, the suitable densities of NiS in Pt-Ni NWs-S/C are important factors to produce the desirable $\mathrm{Pt}_{3} \mathrm{Ni} / \mathrm{NiS}$ interfaces for largely enhancing the alkaline HER activity. All the experimental and theoretical data prove that the unique interface between $\mathrm{Pt}_{3} \mathrm{Ni}$ NWs and NiS nanoparticles is the main factor in promoting the HER activity enhancement in the alkaline condition. However, the more detailed role of sulfide and electrocatalytic mechanism of $\mathrm{PtNi} / \mathrm{NiS} \mathrm{NWs}$ under the basic condition are still not very clear. The partial reason is that the existent corrosion and coordination effect in the basic condition might affect the apparent structure of catalysts, resulting in the electrocatalytic mechanism more complex. The in situ spectroscopic techniques may be good for tracking the catalytic mechanism of $\mathrm{Pt}_{3} \mathrm{Ni} / \mathrm{NiS}$ interface nanowires during the HER process in the electrolytes with different $\mathrm{pH}$, which will be our future endeavour.

In summary, we demonstrate a new procedure for making the $\mathrm{Pt}_{3} \mathrm{Ni} / \mathrm{NiS}$ interface NWs with tunable interfaces by the direct sulfuration of highly composition-segregated Pt-Ni NWs. Owing to the optimized synergistic effects between $\mathrm{Pt}_{3} \mathrm{Ni}$ and $\mathrm{NiS}$ interface, the $\mathrm{Pt}_{3} \mathrm{Ni}_{2} \mathrm{NWs}-\mathrm{S} / \mathrm{C}$ exhibit much enhanced performance compared with the pristine $\mathrm{Pt}_{3} \mathrm{Ni}_{2} \mathrm{NWs} / \mathrm{C}$ and the commercial $\mathrm{Pt} / \mathrm{C}$ for alkaline HER. In particular, the $\mathrm{Pt}_{3} \mathrm{Ni}_{2}$ NWs-S/C display the best HER activity at $\mathrm{pH}$ 14, far exceeding the other Pt-Ni NWs-S/C. The $\mathrm{Pt}_{3} \mathrm{Ni}_{2}$ NWs-S/C can reach a 
current density of $37.2 \mathrm{~mA} \mathrm{~cm}^{-2}$ at $0.07 \mathrm{~V}$, at $\mathrm{pH} 14$, over 9.7 times higher than the commercial $\mathrm{Pt} / \mathrm{C}\left(3.83 \mathrm{~mA} \mathrm{~cm}^{-2}\right)$. The DFT calculations reveal that NiS could promote water dissociation to generate $\mathrm{H}^{+}$while $\mathrm{Pt}_{3} \mathrm{Ni}$ can effectively convert $\mathrm{H}^{+}$to $\mathrm{H}_{2}$. The synergy between the $\mathrm{NiS}$ and $\mathrm{Pt}_{3} \mathrm{Ni}$ components thus underlies the much increased HER activity in the alkaline solution. These multicomponent NWs also exhibit enhanced durability. This study highlights a novel strategy to create metal/ sulfide heterostructures with excellent electrocatalytic performance for alkaline HER and beyond.

\section{Methods}

Chemicals. Platinum (II) acetylacetonate (Pt(acac) 2 , 97\%), nickel (II) acetylacetonate $\left(\mathrm{Ni}(\mathrm{acac})_{2}, 95 \%\right)$, hexadecyltrimethylammonium chloride $\left(\mathrm{CH}_{3}\left(\mathrm{CH}_{2}\right)_{15} \mathrm{~N}(\mathrm{Cl})\left(\mathrm{CH}_{3}\right)_{3}, \mathrm{CTAC},>98.0 \%\right)$ and $\mathrm{OAm}\left(\mathrm{CH}_{3}(\mathrm{CH} 2)_{7} \mathrm{CH}=\right.$ $\left.\mathrm{CH}\left(\mathrm{CH}_{2}\right)_{7} \mathrm{CH}_{2} \mathrm{NH}_{2}, 70 \%\right)$ were all purchased from Sigma-Aldrich. Glucose $\left(\mathrm{C}_{6} \mathrm{H}_{12} \mathrm{O}_{6}, \mathrm{AR}\right)$ and sulfur powder $(\mathrm{S}, \mathrm{CP})$ were purchased from Sinopharm Chemical Reagent Co. Ltd. (Shanghai, China). All the chemicals were used as received without further purification. The water $\left(18 \mathrm{M} \Omega \mathrm{cm}^{-1}\right)$ used in all experiments was prepared by passing through an ultra-pure purification system.

Preparation of Pt-Ni nanowires. Pt-Ni NWs were synthesized according to a previously reported method with slight modification ${ }^{27}$. In a typical preparation of $\mathrm{Pt}_{3} \mathrm{Ni}_{x}\left(x=1,2,3\right.$ and 4) NWs, $10 \mathrm{mg} \mathrm{Pt}(\mathrm{acac})_{2}$, a desirable amount of $\mathrm{Ni}(\mathrm{acac})_{2}$ (that is, 2.3, 4.6, 6.8 and 9.1), $32 \mathrm{mg}$ CTAC, $60 \mathrm{mg}$ glucose and $5 \mathrm{ml}$ OAm were added into a vial (volume: $30 \mathrm{ml}$ ). After the vial had been capped, the mixture was ultrasonicated for $1 \mathrm{~h}$. The resulting homogeneous mixture was then heated from room temperature to $180^{\circ} \mathrm{C}$ and maintained at $180^{\circ} \mathrm{C}$ for $5 \mathrm{~h}$ in an oil bath. After cooling to room temperature, the resulting products were collected by centrifugation and washed several times with ethanol/cyclohexane mixture.

Preparation of Pt-Ni-S NWs. To the unpurified Pt-Ni NWs mixture at $150^{\circ} \mathrm{C}$, $3 \mathrm{mg}$ sulfur powder dissolved in $1 \mathrm{ml}$ OAm was added under magnetic stirring. The mixture was then kept at $150^{\circ} \mathrm{C}$ for another $3 \mathrm{~h}$. The final products were collected by centrifugation and washed three times with an ethanol/cyclohexane mixture.

Characterization. TEM and HAADF-STEM images were conducted on an FEI Tecnai F20 TEM at an acceleration voltage of $200 \mathrm{kV}$. SEM images were taken with a HITACHI S-4700 cold field-emission SEM operated at $15 \mathrm{kV}$. The samples were prepared by dropping cyclohexane dispersion of samples onto carbon-coated copper TEM grids using pipettes and dried under ambient condition. PXRD patterns were collected on X'Pert-Pro MPD diffractometer (Netherlands PANalytical) with a $\mathrm{Cu} \mathrm{K} \alpha \mathrm{X}$-ray source $(\lambda=1.540598 \AA)$. The concentrations of catalysts were determined by the ICP-AES (710-ES, Varian, ICP-AES). XPS was carried out on an SSI S-Probe XPS Spectrometer. The carbon peak at $284.6 \mathrm{eV}$ was used as a reference to correct for charging effects.

Electrochemical measurements. Electrochemical measurements were performed by using CHI660 electrochemical workstation (Chenhua, Shanghai). A three-electrode cell was used to perform the electrochemical measurements. The working electrode was a rotating disk electrode (RDE) (diameter: $5 \mathrm{~mm}$, area: $0.196 \mathrm{~cm}^{2}$ ) from Pine Instruments. A saturated calomel electrode and platinum wire were used as the reference and counter electrodes, respectively. The catalyst ink was prepared by ultrasonically mixing catalysts with $895 \mu \mathrm{l}$ of ethanol, $100 \mu \mathrm{l}$ of water and $5 \mu \mathrm{l}$ of $5 \mathrm{wt} \%$ Nafion solutions for $1 \mathrm{~h}$. The actual mass concentrations of the Pt species in all catalyst inks were controlled at $0.30 \mathrm{mg}_{\mathrm{Pt}}$ per $\mathrm{ml}$. Then, 10 and $50 \mu \mathrm{l}$ of the ink were deposited on RDE dried at room temperature, to obtain the working electrodes for activity and stability test, respectively. The loading of $\mathrm{Pt}$ on the working electrodes were 15.3 and $76.5 \mu \mathrm{g} \mathrm{cm}^{-2}$ for activity test and stability test, respectively.

HER measurements were conducted in $\mathrm{pH}$ values of $14,13,1$ and 0 . All the fresh electrolytes with required concentrations were prepared in a volumetric flask by dissolving the required amount of $\mathrm{KOH}$ or $\mathrm{H}_{2} \mathrm{SO}_{4}$ in Milli-Q water and purged with $\mathrm{N}_{2}$ before the measurement. During the measurement, RDE electrode was constantly rotating at 1,600 r.p.m. to get rid of the bubbles. Linear sweep voltammetry was carried out between -0.2 and $0.2 \mathrm{~V}$ at the scan rate of $10 \mathrm{mV} \mathrm{s}^{-1}$ for activity tests. The catalysts were cycled about 20 cycles at the scan rate of $100 \mathrm{mV} \mathrm{s}^{-1}$ between -0.2 and $0.2 \mathrm{~V}$ until a stable cyclic voltammetry curve was developed before linear sweep voltammetry test. The

chronopotentiometry was measured under a constant current density of $5 \mathrm{~mA} \mathrm{~cm}^{-2}$ for stability test.

For comparison, the commercial Pt/C (20\% loading, 2-5 nm Pt size, Johnson Matthey) was used as the baseline catalyst with the same loading amount of Pt at $15.3 \mu \mathrm{g} \mathrm{cm}^{-2}$ for activity test and $76.5 \mu \mathrm{g} \mathrm{cm}^{-2}$ for stability test. The polarization curves with or without insulation resistance compensation are mentioned in the paper. All electrochemical measurements were performed at room temperature.
DFT models and calculations. Spin-polarized DFT calculations were carried out using the VASP package ${ }^{36,37}$ with the projector-augmented wave pseudopotentials ${ }^{38}$ and Perdew-Burke-Ernzerhof generalized gradient approximation $^{39}$. An energy cutoff of $400 \mathrm{eV}$ was used for the plane-wave basis set The Pt (111), $\mathrm{Pt}_{3} \mathrm{Ni}(111)$ and $\mathrm{NiS}$ (100) surfaces were modelled by periodically repeated four-layer slabs with $(3 \times 3)$ unit cells. The Brillouin zone was sampled with the Monkhorst-Pack scheme ${ }^{40}$ and $3 \times 3 \times 1 \mathrm{k}$-point mesh. The atoms in the top three layers were fully relaxed, while the rest of the atoms were fixed in their equilibrium positions. The force convergence criterion for atomic relaxation was $0.02 \mathrm{eV} \AA^{-1}$

To determine the transition state for water dissociation on the Pt (111) and NiS (100) surfaces, we employed the climbing image nudged elastic band method ${ }^{41}$. Furthermore, the force convergence tolerance on each atom in search of the minimum energy path was set to be $0.05 \mathrm{eV}^{-1}$. The free energy diagram for HER was obtained by calculating the change of the free energy with a hydrogen atom adsorbed on the surface following the computational hydrogen electrode model ${ }^{35}$ The hydrogen adsorption free energy $G_{\mathrm{H}^{*}}$ is determined as

$G_{\mathrm{H}^{*}}=E[$ surf $+\mathrm{H}]-E[$ surf $]-E\left[\mathrm{H}_{2}\right] / 2+\Delta E_{\mathrm{ZPE}}-T \Delta S$, where $E[$ surf $+\mathrm{H}]$ and $E$ [surf] are the total energies of the surface with and without the $\mathrm{H}$ adsorbate, respectively. $E\left[\mathrm{H}_{2}\right]$ is the total energy of a hydrogen molecule. $\Delta E_{\mathrm{ZPE}}$ is the difference in the zero-point energy between the adsorbed $\mathrm{H}$ atom and the gaseous phase $\mathrm{H}_{2} ; \Delta S$ is the difference in entropy. At $T=300 \mathrm{~K}, G_{\mathrm{H}^{*}}$ can be calculated by $\mathrm{G}_{\mathrm{H}^{*}}=E[$ surf $+\mathrm{H}]-E[$ surf $]-E\left[\mathrm{H}_{2}\right] / 2+0.24 \mathrm{eV}^{35}$.

Data availability. All relevant data are available from the authors on request.

\section{References}

1. Walter, M. G. et al. Solar water splitting cells. Chem. Rev. 110, 6446-6473 (2010).

2. Nocera, D. G. The artificial leaf. Acc. Chem. Res. 45, 767-776 (2012).

3. Dresselhaus, M. S. \& Thomas, I. L. Alternative energy technologies. Nature 414, 332-337 (2001).

4. Crabtree, G. W., Dresselhaus, M. S. \& Buchanan, M. V. The hydrogen economy. Phys. Today 57, 39-44 (2004).

5. Abbasi, T. \& Abbasi, S. A. 'Renewable' hydrogen: prospects and challenges. Renew. Sust. Energy Rev. 15, 3034-3040 (2011).

6. Yin, H. \& Tang, Z. Ultrathin two-dimensional layered metal hydroxides: an emerging platform for advanced catalysis, energy conversion and storage. Chem. Soc. Rev. 45, 4873-4891 (2016).

7. Turner, J. A. Sustainable hydrogen production. Science 305, 972-974 (2004).

8. Zeng, K. \& Zhang, D. Recent progress in alkaline water electrolysis for hydrogen production and applications. Prog. Energy Combust. Sci. 36, 307-326 (2010).

9. Lu, Q., Yu, Y., Ma, Q., Chen, B. \& Zhang, H. 2D transition-metaldichalcogenide-nanosheet-based composites for photocatalytic and electrocatalytic hydrogen evolution reactions. Adv. Mater. 28, 1917-1933 (2016).

10. Gandía, L. M., Oroz, R., Ursúa, A., Sanchis, P. \& Diéguez, P. M. Renewable hydrogen production: performance of an alkaline water electrolyzer working under emulated wind conditions. Energy Fuels 21, 1699-1706 (2007).

11. Vilekar, S. A., Fishtik, I. \& Datta, R. Kinetics of the hydrogen electrode reaction. J. Electrochem. Soc. 157, B1040-B1050 (2010).

12. Durst, J. et al. New insights into the electrochemical hydrogen oxidation and evolution reaction mechanism. Energy Environ. Sci. 7, 2255-2260 (2014).

13. Subbaraman, R. et al. Enhancing hydrogen evolution activity in water splitting by tailoring $\mathrm{Li}^{+}-\mathrm{Ni}(\mathrm{OH})_{2}$-Pt interfaces. Science 334, 1256-1260 (2011).

14. Yin, H. et al. Ultrathin platinum nanowires grown on single-layered nickel hydroxide with high hydrogen evolution activity. Nat. Commun. 6, 6430 (2015).

15. Norskov, J. K. \& Christensen, C. H. Toward efficient hydrogen production at surfaces. Science 312, 1322-1323 (2006).

16. Esposito, D. V. et al. Low-cost hydrogen-evolution catalysts based on monolayer platinum on tungsten monocarbide substrates. Angew. Chem. Int. Ed. 49, 9859-9862 (2010).

17. Bai, S. et al. Surface polarization matters: enhancing the hydrogen-evolution reaction by shrinking Pt shells in Pt-Pd-graphene stack structures. Angew. Chem. Int. Ed. 53, 12120-12124 (2014).

18. Li, Q. et al. New approach to fully ordered fct-FePt nanoparticles for much enhanced electrocatalysis in acid. Nano Lett. 15, 2468-2473 (2015).

19. Markovića, N. M., Sarraf, S. T., Gasteiger, H. A. \& Ross, P. N. Hydrogen electrochemistry on platinum low-index single-crystal surfaces in alkaline solution. J. Chem. Soc. Faraday Trans. 92, 3719-3725 (1996).

20. Rheinländer, P., Henning, S., Herranz, J. \& Gasteiger, H. A. Comparing hydrogen oxidation and evolution reaction kinetics on polycrystalline platinum in $0.1 \mathrm{M}$ and $1 \mathrm{M}$ KOH. ECS Trans. 50, 2163-2174 (2013).

21. Greeley, J., Jaramillo, T. F., Bonde, J., Chorkendorff, I. B. \& Norskov, J. K. Computational high-throughput screening of electrocatalytic materials for hydrogen evolution. Nat. Mater. 5, 909-913 (2006). 
22. Henderson, M. A. The interaction of water with solid surfaces: fundamental aspects revisited. Surf. Sci. Rep. 46, 1-308 (2002).

23. Wang, P., Jiang, K., Wang, G., Yao, J. \& Huang, X. Phase and interface engineering of platinum-nickel nanowires for efficient electrochemical hydrogen evolution. Angew. Chem. Int. Ed. 55, 12859-12863 (2016).

24. Chen, C. et al. Highly crystalline multimetallic nanoframes with threedimensional electrocatalytic surfaces. Science 343, 1339-1343 (2014).

25. Gan, L. et al. Element-specific anisotropic growth of shaped platinum alloy nanocrystals. Science 346, 1502-1506 (2014).

26. Fan, Z. et al. Synthesis of $4 \mathrm{H} / \mathrm{fcc}$ noble multimetallic nanoribbons for electrocatalytic hydrogen evolution reaction. J. Am. Chem. Soc. 138, 1414-1419 (2016).

27. Li, Z. et al. Platinum-nickel frame within metal-organic framework fabricated in situ for hydrogen enrichment and molecular sieving. Nat. Commun. 6, 8248 (2015).

28. Ding, J. et al. Morphology and phase controlled construction of Pt-Ni nanostructures for efficient electrocatalysis. Nano Lett. 16, 2762-2767 (2016).

29. Oh, A. et al. Skeletal octahedral nanoframe with cartesian coordinates via geometrically precise nanoscale phase segregation in a Pt@Ni core-shell nanocrystal. ACS Nano 9, 2856-2867 (2015).

30. Shui, J. I., Chen, C. \& Li, J. C. M. Evolution of nanoporous Pt-Fe alloy nanowires by dealloying and their catalytic property for oxygen reduction reaction. Adv. Funct. Mater. 21, 3357-3362 (2011).

31. Bu, L. et al. A general method for multimetallic platinum alloy nanowires as highly active and stable oxygen reduction catalysts. Adv. Mater. 27, 7204-7212 (2015).

32. Ahrenstorf, K. et al. Colloidal synthesis of $\mathrm{Ni}_{\mathrm{X}} \mathrm{Pt}_{1-\mathrm{x}}$ nanoparticles with tuneable composition and size. Small 3, 271-274 (2007).

33. Huang, $\mathrm{X}$. et al. A facile strategy to $\mathrm{Pt}_{3} \mathrm{Ni}$ nanocrystals with highly porous features as an enhanced oxygen reduction reaction catalyst. Adv. Mater. 25, 2974-2979 (2013).

34. Vrubel, H., Merki, D. \& Hu, X. Hydrogen evolution catalyzed by $\mathrm{MoS}_{3}$ and $\mathrm{MoS}_{2}$ particles. Energy Environ. Sci. 5, 6136-6144 (2012).

35. Nørskov, J. K. et al. Trends in the exchange current for hydrogen evolution. J. Electrochem. Soc. 152, J23-J26 (2005).

36. Kresse, G. \& Hafner, J. Ab initio molecular dynamics for liquid metals. Phys. Rev. B 47, 558-561 (1993).

37. Kresse, G. \& Furthmüller, J. Efficient iterative schemes for $a b$ initio total-energy calculations using a plane-wave basis set. Phys. Rev. B 54, 11169-11186 (1996).

38. Blöchl, P. E. Projector augmented-wave method. Phys. Rev. B 50, 17953-17979 (1994).

39. Perdew, J. P., Burke, K. \& Ernzerhof, M. Generalized gradient approximation made simple. Phys. Rev. Lett. 77, 3865-3868 (1996).

40. Monkhorst, H. J. \& Pack, J. D. Special points for Brillouin-zone integrations Phys. Rev. B 13, 5188-5192 (1976).

41. Henkelman, G., Uberuaga, B. P. \& Jónsson, H. A climbing image nudged elastic band method for finding saddle points and minimum energy paths. J. Chem. Phys. 113, 9901-9904 (2000).

\section{Acknowledgements}

This work was financially supported by Ministry of Science and Technology (2016YFA0204100), the National Natural Science Foundation of China (21571135 and 51671003), National Basic Research Program of China (number 2016YFB0100201),

Young Thousand Talented Program, the start-up supports from Soochow University and Peking University, and the Priority Academic Program Development of Jiangsu Higher Education Institutions (PAPD). The work at California State University Northridge was supported by the US Army Research Office via the MURI grant W911NF-11-1-0353.

\section{Author contributions}

X.H. and S.G. conceived and supervised the research. X.H., P.W. and J.Z. designed the experiments. X.H., P.W., J.Z., X.Z., S.G. and G.L. performed most of the experiments and data analysis. X.H., P.W., X.Z., J.Z., S.W., S.G., G.L. and J.Y. participated in various aspects of the experiments and discussions. X.Z. and G.L. performed the DFT simulations. X.H., S.G. and P.W. wrote the paper. All authors discussed the results and commented on the manuscript.

\section{Additional information}

Supplementary Information accompanies this paper at http://www.nature.com/ naturecommunications

Competing financial interests: The authors declare no competing financial interests.

Reprints and permission information is available online at http://npg.nature.com/ reprintsandpermissions/

How to cite this article: Wang, P. et al. Precise tuning in platinum-nickel/nickel sulfide interface nanowires for synergistic hydrogen evolution catalysis. Nat. Commun. 8, 14580 doi: $10.1038 /$ ncomms14580 (2017).

Publisher's note: Springer Nature remains neutral with regard to jurisdictional claims in published maps and institutional affiliations.

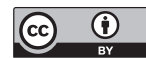

This work is licensed under a Creative Commons Attribution 4.0 International License. The images or other third party material in this article are included in the article's Creative Commons license, unless indicated otherwise in the credit line; if the material is not included under the Creative Commons license, users will need to obtain permission from the license holder to reproduce the material. To view a copy of this license, visit http://creativecommons.org/licenses/by/4.0/

(C) The Author(s) 2017 